RAMOS, M.B.M.; VIEIRA, M.C.; HEREDIA Z., N.A.; SIQUEIRA, J.M.; ZIMINIANI, M.G. Produção de capítulos florais em função de populações de plantas e da incorporação ao solo de cama-de-aviário. Horticultura Brasileira, Brasília, v.22, n.3, p.566-572, jul-set 2004.

\title{
Produção de capítulos florais da camomila em função de populações de plantas e da incorporação ao solo de cama-de-aviário ${ }^{1}$
}

\author{
Marisa B.M. Ramos²; Maria do Carmo Vieira²*; Néstor A. Heredia Zárate²*; João M. de Siqueira²; Maria \\ Graziela Ziminiani ${ }^{3}$ \\ ${ }^{2}$ UFMS, C. Postal 533, 79804-970 Dourados-MS; ${ }^{3}$ Bolsista PIBIC/CNPq; *Bolsistas CNPq; E-mail: mcvieira@ @eud.ufms.br
}

\begin{abstract}
RESUMO
O experimento foi realizado no horto de plantas medicinais da Universidade Federal de Mato Grosso do Sul, em Dourados, de abril a setembro/2000. Avaliou-se o efeito do uso de cama-de-aviário semidecomposta incorporada ao solo e populações de plantas sobre as características morfológicas, a produção e a qualidade do óleo essencial dos capítulos florais da camomila cv. 'Mandirituba'. Os fatores em estudo deram origem aos nove tratamentos, combinando respectivamente espaçamentos entre plantas $(\mathrm{m})$ e cama-de-aviário $\left(\mathrm{kg} \mathrm{m}^{-2}\right): 0,16$ e 1,$2 ; 0,24$ e 1,$2 ; 0,16$ e 2,$8 ; 0,24$ e 2,$8 ; 0,20$ e 2,0; 0,11 e 1,$2 ; 0,29$ e 2,$8 ; 0,16$ e 0,2 e 0,24 e 3,8 , dispostos no delineamento experimental de blocos casualizados, com quatro repetições. As características avaliadas foram altura de plantas; número, altura e diâmetro, massa fresca e seca e análise qualitativa do óleo essencial dos capítulos florais. A altura média máxima das plantas da camomila 'Mandirituba' foi de $0,61 \mathrm{~m}$, sendo considerada cultivar de porte baixo. Não houve efeito significativo da interação espaçamentos entre plantas e cama-de-aviário sobre as características avaliadas. A produção dos capítulos florais foi influenciada mais intensamente pelo espaçamento entre plantas do que pela cama-deaviário. $\mathrm{O}$ menor espaçamento induziu os maiores números $(56,57$ milhões ha-1) e massas secas dos capítulos florais $\left(1.080 \mathrm{~kg} \mathrm{ha}^{-1}\right)$. As alturas $(0,71$ a $0,81 \mathrm{~cm}$ aos 100 dias e 0,68 a $0,71 \mathrm{~cm}$ aos 116 dias após transplante), o diâmetro (1,96 a 2,13 cm aos 100 dias e 1,83 a $1,91 \mathrm{~cm}$ aos 116 dias após transplante) e a massa unitária dos capítulos florais $(0,12 \mathrm{~g})$ não foram significativamente influenciados pelos tratamentos estudados. A produção média de massa seca dos capítulos florais ( $\left.800 \mathrm{~kg} \mathrm{ha}^{-1}\right)$ foi maior que a média brasileira convencional $\left(500 \mathrm{~kg} \mathrm{ha}^{-1}\right)$. O óleo essencial obtido, nas amostras dos nove tratamentos, apresentou cor azul intensa e odor característico, como descrito na literatura para os óleos de boa qualidade e apropriados para a comercialização.
\end{abstract}

Palavras-chave: Chamomilla recutita sin., Matricaria chamomilla, Asteraceae, resíduo orgânico, controle de qualidade, CCD em sílica gel, perfil cromatográfico.

\begin{abstract}
Production of capitula of chamomile as a result of plant populations and chicken manure incorporated to the soil
\end{abstract}

This experiment was carried out in the Universidade Federal de Mato Grosso do Sul, Mato Grosso State, Brazil, from April to September 2000, on a dystrorthox soil, clay texture. The use of semidecomposed chicken manure, morphological characteristics of plant populations, yield and essential oil quality of chamomile capitula cv. 'Mandirituba' were evaluated. The evaluated treatments, which combined, respectively, plant spacing $(\mathrm{m})$ and levels of chicken manure $\left(\mathrm{kg} \mathrm{m}^{-2}\right)$ were: 0.16 and $1.20 ; 0.24$ and $1.20 ; 0.16$ and 2.80; 0.24 and $2.80 ; 0.20$ and $2.00 ; 0.11$ and $1.20 ; 0.29$ and $2.80 ; 0.16$ and 0.20 and 0.24 and 3.80, arranged in a randomized block design with four replications. Evaluated characteristics were plant height, number and height and diameter of capitula; fresh and dry matter of capitula and qualitative analysis of capitula essential oil. Maximum average height of 'Mandirituba' chamomile plants was $0,61 \mathrm{~m}$, being considered as small-sized plants. There was no significant effect of spacing among plants/chicken manure level interaction on evaluated characteristics. Production of capitula was more intensively influenced by spacing among plants than by chicken manure. The smallest space resulted in the highest number of capitula $(56,573,000$ $\left.\mathrm{ha}^{-1}\right)$ and in the highest amount of dry matter production $(1,08 \mathrm{~kg}$ ha1). Heights ( 0.71 to $0.81 \mathrm{~cm}$ at 100 days and 0.68 to $0.71 \mathrm{~cm}$ at 116 days after transplant), diameter (1.96 to $2.13 \mathrm{~cm}$ at 100 days and 1.83 to $1.91 \mathrm{~cm}$ at 116 days after transplant) and average mass per capitulum $(0.12 \mathrm{~g})$ were not influenced significantly by studied treatments. The average dry matter production of capitula $(800 \mathrm{~kg}$ $\left.\mathrm{ha}^{-1}\right)$ was higher than conventional Brazilian average $\left(500 \mathrm{~kg} \mathrm{ha}^{-1}\right)$. Essential oil samples extracted from capitula from the nine treatments showed intense blue color and characteristic fragrance, indicating the good quality of the oil.

Keywords: Chamomilla recutita sin. Matricaria chamomilla, Asteraceae, organic residue, quality control, CCD in gel silica.

\section{(Recebido para publicação em 24 de abril de 2003 e aceito em 30 de março de 2004)}

\begin{abstract}
A camomila (Chamomilla recutita (L.) Rauschter sinonímia Matricaria chamomilla L., Asteraceae) é originária da Europa e Norte da África e, atualmente, está dispersa em praticamente todos os continentes (Amat, 1982; Salamon, 1994). No Brasil, foi
\end{abstract}

introduzida pelos imigrantes europeus há mais de 100 anos. Atualmente, é a planta medicinal com a maior área de cultivo e com o maior envolvimento de pequenos produtores rurais. Apesar disso, é considerada cultura secundária, na qual utilizam-se técnicas inadequadas de produção e de beneficiamento, que resultam em produtos de baixa qualidade (Corrêa Júnior e Taniguchi, 1992). Segundo Dalla Costa (2001), no país produz-se o suficiente para o consumo interno, cerca de 150 toneladas de capítulos florais secos por ano, e se a produ-

${ }^{1}$ Parte da dissertação de mestrado do primeiro autor apresentada à UFMS, para obtenção do título de Mestre em Agronomia. Apoio financeiro: CNPq e FUNDECT-MS. 
ção aumentar e os capítulos produzidas forem de boa qualidade, é possível a exportação, principalmente para a Europa, onde o consumo é grande.

Os capítulos florais da camomila contêm óleos essenciais e flavonóides e são utilizados na medicina popular, pelas suas propriedades carminativas, espasmolíticas e antiinflamatórias (Robbers et al., 1996), dentre outras (Salamon, 1994; Rodríguez et al., 1996; Silva, 1999). As atividades antiinflamatória e antiespasmódica estão relacionadas aos principais constituintes encontrados no óleo essencial (sesquiterpenos, derivados do bisabolol) e lactonas guaianolídicas (procamazuleno), e o efeito espasmolítico aos flavonóides (Robbers et al., 1996). O teor de óleo essencial dos capítulos florais pode variar de 0,3 a $1,5 \%$, mas só são comercializados aqueles com teor mínimo de $0,4 \%$, de acordo com a Farmacopéia Brasileira (Donalísio, 1985; Corrêa Júnior et al., 1994; Farias, 1999) e de 0,5 a $3 \%$ de flavonóides totais (Wagner e Bladt, 1996).

Estudos sobre aspectos agronômicos da camomila no Brasil são muito escassos, apesar de apresentar-se como alternativa para rotação de culturas típicas de inverno e como fonte de renda para os proprietários de pequenas áreas. Dentre as necessidades primárias de estudo têm-se a adubação mineral e/ou orgânica e as populações de plantas, que podem contribuir para a maior produção de biomassa e de metabólitos secundários. Em geral, recomenda-se o uso de 2,0 a $5,0 \mathrm{~kg} \mathrm{~m}^{-2}$ de esterco de curral curtido ou composto orgânico ou $2,5 \mathrm{~kg} \mathrm{~m}^{-}$ ${ }^{2}$ de esterco de aves (Corrêa Júnior et al., 1994; Maia e Furlani, 1996). Pesquisas feitas com camomila, fora do Brasil, indicam que dentre os macronutrientes, a aplicação de $40 \mathrm{~kg}$ $\mathrm{ha}^{-1} \mathrm{de} \mathrm{N}$ na forma de sulfato de amônio proporcionou aumento significativo de até $29,1 \%$ na produção dos capítulos florais e de óleo essencial; o uso de fósforo e potássio teve pequeno efeito na produção de biomassa ou de óleo essencial (El-Hamidi et al., 1965). Segundo Chandra e Kappor (1971), a aplicação de $45 \mathrm{~kg} \mathrm{ha}^{-1}$ de fertilizantes nitrogenados teve notável efeito sobre a produção de capítulos florais e o ren- dimento de óleo essencial; por outro lado, a aplicação de fósforo (90 $\mathrm{kg} \mathrm{ha}^{-1}$ de $\mathrm{P}_{2} \mathrm{O}_{5}$ ) e potássio $\left(202 \mathrm{~kg} \mathrm{ha}^{-1}\right.$ de $\left.\mathrm{K}_{2} \mathrm{O}\right)$ teve efeito insignificante sobre a produção de inflorescências, em uma média de quatro colheitas. Conforme Madueño Box (1973) a camomila responde melhor aos adubos nitrogenados e potássicos.

Estudando o efeito de esterco bovino (40 $\mathrm{t} \mathrm{ha}^{-1}$ ), adubos verdes (Mucuna aterriba + Crotalaria spectabilis) e adubação química $\left(80 \mathrm{~kg} \mathrm{ha}^{-1}\right.$ de $\mathrm{N}$ na forma de uréia; $80 \mathrm{~kg} \mathrm{ha}^{-1}$ de $\mathrm{N}$ na forma de sulfato de amônio e $34 \mathrm{~kg} \mathrm{ha}^{-1} \mathrm{de} \mathrm{N}$, $120 \mathrm{~kg} \mathrm{ha}^{-1}$ de $\mathrm{P}_{2} \mathrm{O}_{5}$ e $69 \mathrm{~kg} \mathrm{ha}^{-1}$ de $\mathrm{K}_{2} \mathrm{O}$ da fórmula 4-14-8) na produção da camomila cv. Mandirituba e do seu óleo essencial, Corrêa Júnior (1994) observou que os tratamentos não influenciaram a altura de plantas $(0,24 \mathrm{~m}$ até o início do florescimento e entre 0,45 a $0,48 \mathrm{~m}$ na última colheita), a produção de matéria seca dos capítulos florais (média de $886 \mathrm{~kg} \mathrm{ha}^{-1}$ ) e nem a quantidade percentual média de óleo essencial $(0,84 \%)$. Por outro lado, o uso dos adubos verdes induziu aumento da quantidade percentual de camazuleno $(10,17 \%$, maior que a média mundial), e de óleo essencial $(0,46 \%$ maior que os $0,40 \%$ que a Farmacopéia Brasileira aceita como teor mínimo) e o uso de esterco bovino induziu altura dos capítulos florais entre 5,56 e 6,02 mm, na segunda colheita.

Estudando o crescimento e a produção de capítulos florais da camomila 'Mandirituba' em função de cinco doses de nitrogênio $(3 ; 18 ; 30 ; 42$ e $57 \mathrm{~kg}$ $\mathrm{ha}^{-1}$ ), na forma de sulfato de amônio, e de cinco doses de cama-de-aviário (1.000; 6.000; $10.000 ; 14.000$ e $19.000 \mathrm{~kg}$ ha $^{-1}$ ), Vieira et al. (2001) observaram que no início do florescimento as maiores alturas das plantas $(0,38 \mathrm{~m})$ eram daquelas cultivadas com as maiores doses de $\mathrm{N}$ e de cama-de-aviário. A maior altura dos capítulos florais $(0,75 \mathrm{~m})$ foi obtida com a maior dose de cama-de-aviário, independente da dose de $\mathrm{N}$ utilizada. Os diâmetros dos capítulos florais cresceram significativamente com as doses de $\mathrm{N}$, variando de 1,81 a $2,07 \mathrm{~cm}$. As maiores massas secas de capítulos florais $\left(1.109 \mathrm{~kg} \mathrm{ha}^{-1}\right)$ resultaram da maior dose de nitrogênio ( $\left.57 \mathrm{~kg} \mathrm{ha}^{-1}\right)$ associada com as maiores doses de cama-de-aviário (14.000 e $19.000 \mathrm{~kg} \mathrm{ha}^{-1}$ ). Os maiores números de capítulos florais (cerca de 51,45 milhões ha $^{-1}$ ) foram obtidos com altas doses de cama-de-aviário, associadas com baixas $\left(3,0 \mathrm{kgha}^{-1} \mathrm{de} \mathrm{N}\right)$ ou altas doses de $\mathrm{N}\left(57,0 \mathrm{~kg} \mathrm{ha}^{-1}\right)$.

Os espaçamentos recomendados para a cultura da camomila são bastante variáveis, desde 0,20 a $0,60 \mathrm{~m}$ entre plantas e fileiras (Martins et al., 1998). Apesar de serem mais trabalhosos do que o semeio a lanço, o cultivo em fileiras tem induzido a uma melhor produtividade (Corrêa Júnior et al., 1994). Estudando o teor de óleo essencial e a percentagem de camazuleno no óleo essencial em capítulos florais de diferentes cultivares de camomila da Hungria e do Egito, sob a influência de populações $\left(1,6 ; 3,0\right.$ e 5,3 plantas $\left.\mathrm{m}^{-2}\right)$ e de níveis de adubação nitrogenada (71,4; 142,8 e 214,2 $\mathrm{kg} \mathrm{ha}^{-1}$ de N) Sváb et al. (1967), citados por Corrêa Júnior (1994), não encontraram diferenças significativas nos fatores pesquisados.

Este trabalho teve como objetivo avaliar algumas características morfológicas e a produção de capítulos florais e o perfil cromatográfico do óleo essencial da camomila cv. Mandirituba em função de populações de plantas e da incorporação ao solo de cama-deaviário semidecomposta.

\section{MATERIAL E MÉTODOS}

O trabalho foi desenvolvido de abril a setembro/2000, na Universidade Federal de Mato Grosso do Sul, em Dourados. A cidade tem altitude média de 452 m e clima classificado pelo sistema internacional de Köppen como Cwa Mesotérmico Úmido. A precipitação média anual é de $1500 \mathrm{~mm}$ e a temperatura média anual de $22^{\circ} \mathrm{C}$. A umidade relativa do ar média do período foi de 73,18\% (Estação Agroclimatológica da UFMS). O solo, originalmente sob vegetação de cerrado, é classificado como Latossolo Vermelho distroférrico, de textura argilosa e de topografia plana. Os resultados das análises químicas das amostras do solo, antes do transplante e após a colheita, foram, respectivamente: $\mathrm{pH} \mathrm{H}_{2} \mathrm{O}(1: 2,5)=5,7$ e 6,$0 ; \mathrm{P}(\mathrm{mg}$ $\left.\mathrm{dm}^{-3}\right)=9,0$ e 25,$0 ; \mathrm{K}\left(\mathrm{mmol}_{\mathrm{c}} \mathrm{dm}^{-3}\right)=4,8$ 
e 4,$8 ; \mathrm{Al}^{+3}\left(\mathrm{mmol} \mathrm{dm}^{-3}\right)=3,0$ e 0,$0 ; \mathrm{Ca}^{+2}$ $\left.(\mathrm{mmol} \mathrm{dm})^{-3}\right)=30,0$ e 43,9; $\mathrm{Mg}(\mathrm{mmol}$ $\left.\mathrm{dm}^{-3}\right)=19,0$ e 26,$0 ; \mathrm{H}+\mathrm{Al}\left(\mathrm{mmol} \mathrm{dm}^{-}\right.$ $\left.{ }^{3}\right)=59,2$ e 61,6; SB $\left(\mathrm{mmol} \mathrm{dm}^{-3}\right)=53,8$ e 74,7; CTC $\left(\mathrm{mmol} \mathrm{dm}^{-3}\right)=113,0 \mathrm{e}$ 136,$3 ; \mathrm{V}(\%)=47,0$ e 54,0 e $\mathrm{MO}\left(\mathrm{g} \mathrm{kg}^{-}\right.$ $\left.{ }^{1}\right)=26,3$ e 30,2. A composição da camade-aviário $\left(\mathrm{g} \mathrm{kg}^{-1}\right)$ foi de 205,6; 28,5; 24,3 e 18,7 para $\mathrm{C}_{\text {orgânico }}$ P total, $\mathrm{K}$ total e $\mathrm{N}$ total, respectivamente, e relação $\mathrm{C} /$ $\mathrm{N}=10,99$.

Os fatores em estudo foram cinco espaçamentos entre plantas $(0,11 ; 0,16$; 0,$20 ; 0,24$ e $0,29 \mathrm{~m}$, correspondentes às populações de 239.976, 165.000, 132.000, 109.824 e 90.816 plantas ha ${ }^{-1}$, respectivamente) e cinco doses de camade-aviário semidecomposta $(0,2 ; 1,2$; 2,0; 2,8 e 3,8 $\mathrm{kg} \mathrm{m}^{-2}$ ), distribuídas a lanço e incorporadas ao solo com rotoencanteirador, a uma profundidade de 0,20 m, um dia antes do transplante. A definição dos tratamentos foi feita pelo uso da matriz experimental PLAN PUEBLA III (Turrent e Laird, 1975), que resultou nas seguintes combinações de espaçamentos entre plantas (m) e cama-de-aviário $\left(\mathrm{kg} \mathrm{m}^{-2}\right)$, respectivamente: 0,16 e 1,$2 ; 0,24$ e 1,2; 0,16 e 2,8; 0,24 e 2,$8 ; 0,20$ e 2,$0 ; 0,11$ e 1,$2 ; 0,29$ e 2,$8 ; 0,16$ e 0,2 e 0,24 e 3,8 . O delineamento experimental utilizado foi o de blocos casualizados, com nove tratamentos e quatro repetições. Cada parcela foi composta por um canteiro de $1,08 \mathrm{~m}$ de largura e 1,50 m de comprimento, com quatro fileiras de plantas, espaçadas de 0,27 m entre elas.

Para a propagação foram usadas sementes da camomila 'Mandirituba' provenientes de plantas cultivadas no Horto de Plantas Medicinais, oriundas de sementes doadas pela Emater-PR. As mudas foram produzidas em bandejas e transplantadas ao local definitivo quando as plântulas atingiram cerca de 0,10 $\mathrm{m}$ de altura. $\mathrm{O}$ controle de plantas daninhas foi feito com auxílio de enxada e as irrigações, pelo sistema de aspersão, sempre que necessárias. Não foi utilizado nenhum agrotóxico diretamente na cultura para controle de pragas ou doenças. Como foi observada a presença de Diabrotica speciosa, para evitar prováveis danos à cultura, foram utilizadas armadilhas com cabaças (Lagenaria sp) embebidas com o inseticida Parathion methyl, em dose de $10 \mathrm{ml} \mathrm{L}^{-1}$ de água, distribuídas nas parcelas, alternadamente (Heredia et al., 1998).

Durante o ciclo de cultivo, foram medidas as alturas de todas as plantas das parcelas, a cada dez dias, a partir de 30 até 110 dias após o transplante. Foram feitas dez colheitas manuais dos capítulos florais de todas as plantas, cujas flores liguladas encontravam-se em posição horizontal, a partir de 52 até 122 dias após o transplante. Em cada colheita, foram contados e pesados os capítulos florais e depois, colocados em secador com circulação de ar forçada a $36^{+} 2^{\circ} \mathrm{C}$, até massa constante, para obtenção da matéria seca. Em três épocas, aos 100, 108 e 116 dias após o transplante foram separados, ao acaso, 30 capítulos florais por parcela e medidos, com paquímetro, o diâmetro (incluindo as flores liguladas) e a altura.

Às médias dos dados de altura das plantas, com emprego de polinômios ortogonais, foram ajustadas equações de regressão. A significância dos modelos foi obtida pelo teste $\mathrm{F}$ e os coeficientes de regressão dos modelos selecionados, pelo teste de t até $5 \%$ de probabilidade (Banzatto e Kronka, 1989). Os dados de produção e de características morfológicas dos capítulos florais foram submetidos à análise de variância para determinação do erro experimental da matriz. Para estimar as superfícies de resposta, foram ajustados os modelos quadrático e quadrático base raiz quadrada às médias por tratamento. Cada componente dos modelos foi testado até $5 \%$ de probabilidade, pelo teste $\mathrm{F}$, tendo sido utilizado o quadrado médio do erro experimental da matriz. Cada efeito individual do modelo escolhido foi testado até $10 \%$, pelo teste $\mathrm{F}$, corrigido em função do erro experimental, usando t calculado pelo SAEG (Alvarez V., 1991; Ribeiro Junior, 2001).

As análises quantitativa e qualitativa do óleo essencial dos capítulos florais foram feitas no laboratório de Farmacognosia da UFMS, em Campo Grande (MS). Foram pesados $100 \mathrm{~g}$ de capítulos florais frescos de cada tratamento, trituradas em liqüidificador com mais $300 \mathrm{ml}$ de água destilada, para maior superfície de contato. Utilizaramse aparelhos tipo Clevenger graduados, acoplados a balões volumétricos de fundo redondo de $1000 \mathrm{ml}$, aquecidos por mantas térmicas com termostato, onde as misturas foram colocadas. Para auxiliar no arraste à vapor, foi adicionado em cada balão volumétrico $1 \mathrm{ml}$ de solução xilol. A extração foi mantida por cinco horas a uma temperatura de aproximadamente $100^{\circ} \mathrm{C}$. Após completar o processo, mediu-se a quantidade de óleo extraído, descontando-se $1 \mathrm{ml}$ de xilol $\left(\mathrm{C}_{8} \mathrm{H}_{10}\right.$ - densidade $=0,85-0,87$ a $\left.20^{\circ} \mathrm{C}\right)$. Para a análise qualitativa, uma alíquota de $200 \mu \mathrm{l}$ de cada amostra de óleo essencial foi completada com $1,8 \mathrm{ml}$ de tolueno p.a. e $10 \mu \mathrm{l}$ dessa solução foram aplicados em placa de vidro $20 \mathrm{x}$ 20, coberta com sílica gel MERCK e eluídas em tolueno: acetato de etila (p.a.) 93:7. Após a eluição, a placa foi seca e revelada com vanilina $1 \%$ e ácido sulfúrico $10 \%$, ambos em etanol p.a., seguida de aquecimento (Wagner e Bladt, 1996; Di Stasi, 1996). As cores observadas e os valores de $\mathrm{Rf}^{2}$ (retention factor $=$ fator de retenção de uma determinada substância, quando a mesma é avaliada em um sistema cromatográfico, ou seja, a distância percorrida pela amostra em função do sistema de solvente ou fase móvel em uma determinada fase fixa) das principais substâncias foram anotados.

\section{RESULTADOS E DISCUSSÃO}

As curvas de crescimento em altura das plantas da camomila (Figura 1) variaram pouco em função dos tratamentos, demonstrando que prevaleceu o efeito do componente genético característico do cultivar. A maior altura média $(0,20 \mathrm{~m})$ no início do florescimento, aos 46 dias após transplante, foi observada no tratamento onde se combinou o menor espaçamento entre as plantas $(0,11$ m) e a dose de $1,2 \mathrm{~kg} \mathrm{~m}^{-2}$ de cama-deaviário. No final do ciclo de cultivo, aos 103 dias após transplante, a maior altura $(0,66 \mathrm{~m})$ resultou do tratamento de $0,16 \mathrm{~m}$ entre plantas com $0,2 \mathrm{~kg} \mathrm{~m}^{-2} \mathrm{de}$ cama-de-aviário. O uso do espaçamento de 0,24 m entre plantas, combinado com a maior dose de cama-de-aviário $(3,8 \mathrm{~kg}$ $\left.\mathrm{m}^{-2}\right)$, resultou na menor altura final das plantas $(0,61 \mathrm{~m})$, aos 101 dias após transplante. Esses resultados foram di- 
ferentes daqueles obtidos por Corrêa Júnior (1994), em Jaboticabal (SP), com a camomila 'Mandirituba', onde as alturas das plantas foram de $0,24 \mathrm{~m}$ e 0,45 a $0,48 \mathrm{~m}$, no início do florescimento e final do ciclo de cultivo, respectivamente, permitindo-lhe deduzir que a cultivar era de porte baixo, quando comparou com as alturas finais das cultivares Egito $(0,87 \mathrm{~m})$, Argentina $(0,89 \mathrm{~m})$, Budakalasz 2 (0,91 m), Offstein $(0,96$ $\mathrm{m})$ e Bona (0,93 m), estudadas por Bezzi et al. (1991), na Itália. Ferreira e Braz (1995) também observaram padrão de crescimento diferente em cinco cultivares de camomila, originários da Espanha, Holanda, Hungria, Dinamarca e Argentina, em condições de casade-vegetação, no outono, sendo a maior altura $(0,67 \mathrm{~m})$ do genótipo Argentino e a menor $(0,45 \mathrm{~m})$ daquele da Espanha. As diferenças nas alturas das plantas, encontradas nos distintos locais, podem ser atribuídas, além das diferenças genotípicas, às diferenças climáticas, diferentes características dos solos onde foram realizados os trabalhos ou mesmo a diferenças nas metodologias de medição das plantas.

A maior produção de massa seca dos capítulos florais $\left(1.080 \mathrm{~kg} \mathrm{ha}^{-1}\right)$ foi obtida com o tratamento de $0,11 \mathrm{~m}$ entre plantas e 3,8 $\mathrm{kg} \mathrm{m}^{-2}$ de cama-de-aviário (Figura 2), sendo maior que a média do Brasil e Argentina (500 kg ha ${ }^{-1}$ ) (Corrêa Júnior, 1994) e a da Índia (320 a 480 kg ha $^{-1}$ ) (Chandra e Kappor, 1971), mas ficou dentro da faixa produtiva da Itália (924 a $1683 \mathrm{~kg} \mathrm{ha}^{-1}$ ) (Bezzi et al., 1991). $\mathrm{O}$ fato de a produção máxima ter sido atingida com o menor espaçamento entre plantas indica que não houve competição suficiente para causar redução da produção nas plantas mais adensadas. Peneva (1984), estudando na camomila as densidades de $10 ; 20 ; 40 ; 80$ ou 140 plantas $\mathrm{m}^{-2}$, com fileiras espaçadas de $0,50 \mathrm{~m}$, obteve a maior produção com 40 plantas $\mathrm{m}^{-2}$.

$\mathrm{O}$ aumento linear da produção da massa seca (Figura 2) dos capítulos florais da camomila em relação às doses da cama-de-aviário indica que não se utilizou a dose que induzisse a produção máxima. Isso, provavelmente, seja devido à ação que a cama-de-aviário semidecomposta exerceu na parte físi-

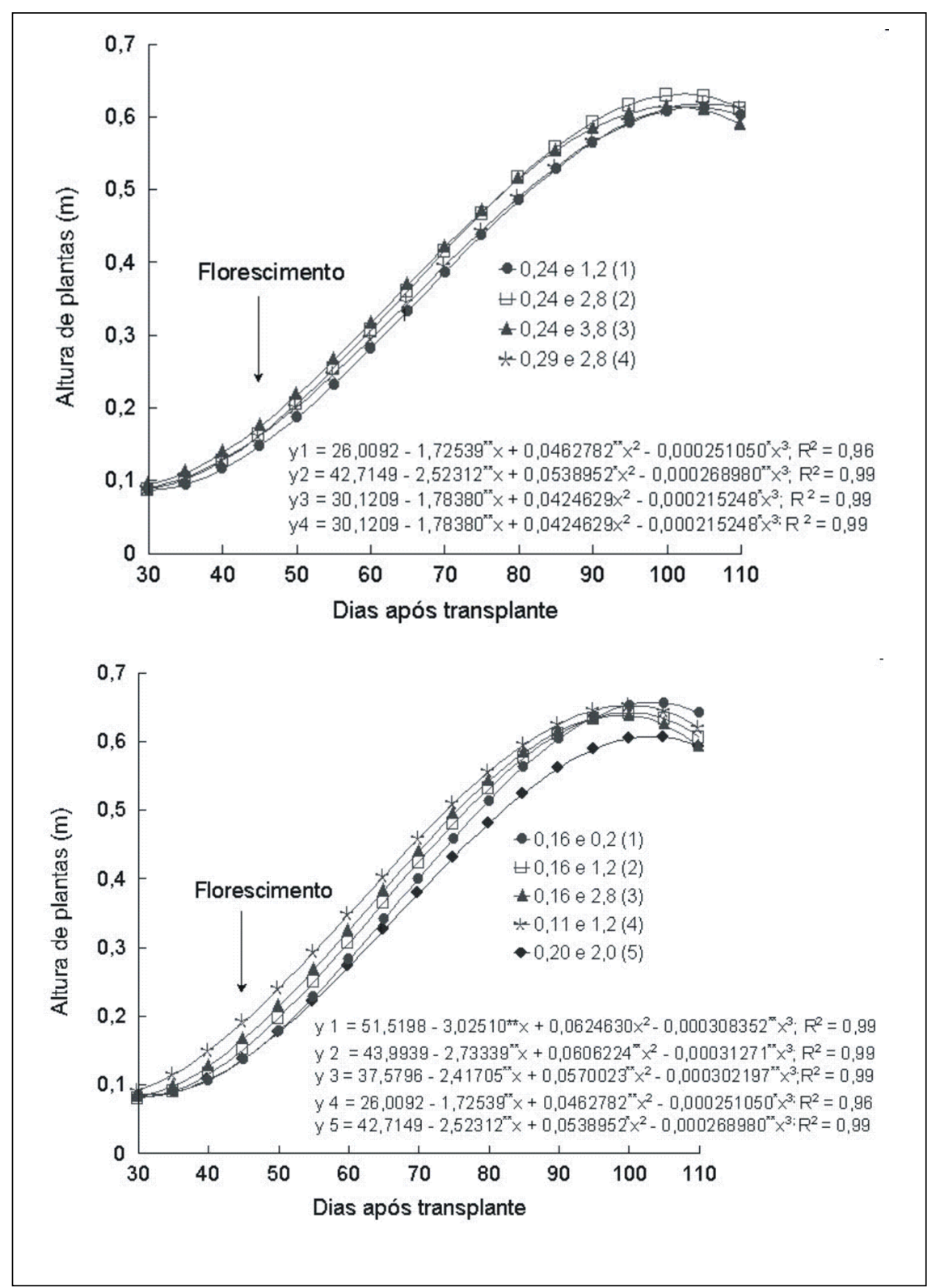

Figura 1. Altura de plantas da camomila (Chamomilla recutita L.) cv. Mandirituba em função de dias após transplante, do uso de cama-de-aviário e de espaçamentos entre plantas. Dourados, UFMS, 2000.

$*_{\text {-e }}^{* *}$ Significativos a 5 e $1 \%$ de probabilidade, respectivamente, pelo teste $\mathrm{F}$.

ca do solo, favorecendo a manutenção da umidade e o desenvolvimento do sistema radicular das plantas, (Alisson, 1973), mas não atuando como adubo orgânico. Corrêa Júnior (1994), utilizando esterco de curral $\left(40 \mathrm{t} \mathrm{ha}^{-1}\right)$ e espaçamento padrão de $0,25 \mathrm{~m}$ x 0,30 m, não verificou, em Jaboticabal (SP), aumento da produção de capítulos florais da camomila 'Mandirituba' e obteve matéria seca média de capítulos de $886 \mathrm{~kg} \mathrm{ha}^{-1}$, atribuindo esse resultado à alta fertilidade do solo onde foi cultivada a espécie e ao fato de a produção de capítulos de camomila ser mais influenciada por outros fatores ambientes do que pela fertilidade do solo. Aguilera $e t$ al. (2000), utilizando as combinações de adubo químico de liberação controlada, osmocote (15-9-12), com húmus de minhoca $\left(\mathrm{T} 1=0 \% ; \mathrm{T} 2=6 \mathrm{~kg} \mathrm{~m}^{-3}\right.$ osmocote $+2 \mathrm{~kg} \mathrm{~m}^{-3}$ húmus; T3 $=4 \mathrm{~kg} \mathrm{~m}^{-3}$ osmocote $+4 \mathrm{k} \mathrm{g} \mathrm{m}^{-3}$ húmus; $\mathrm{T} 4=2 \mathrm{~kg}$ $\mathrm{m}^{-3}$ osmocote $+6 \mathrm{~kg} \mathrm{~m}^{-3}$ húmus e T5 $=8$ $\mathrm{kg} \mathrm{m}^{-3}$ osmocote), constataram que as maiores produções de massa seca dos capítulos de camomila (4,40 e 4,51 g planta $\left.^{-1}\right)$ foram obtidas com os tratamen- 


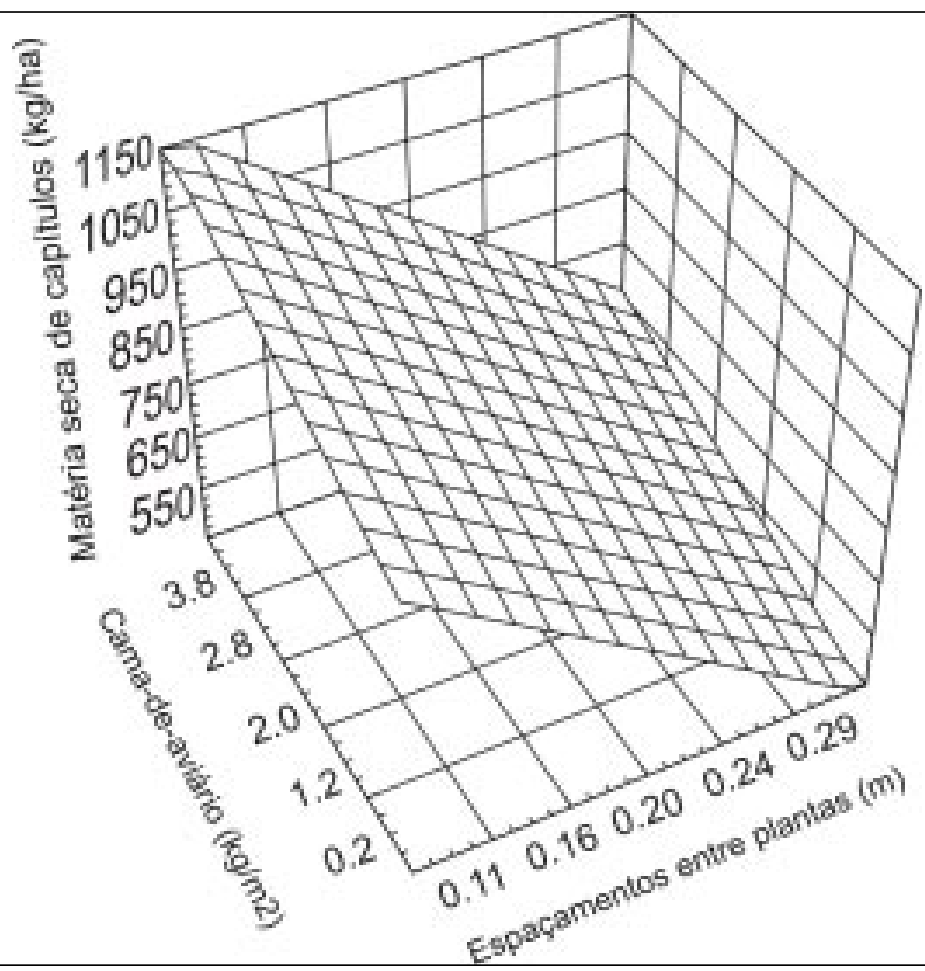

Figura 2. Matéria seca de capítulos florais da camomila (Chamomilla recutita) cv. Mandirituba em função do uso de cama-de-aviário (C) e de espaçamentos (E) entre plantas. C.V. $(\%)=12,96 . \hat{y}=1145,38-2152,46^{* *} \mathrm{E}+45,1041^{\circ} \mathrm{C} ; \mathrm{R}^{2}=0,94 ; * * \mathrm{e}^{\circ}-$ significativos a 1 e $10 \%$ de probabilidade, respectivamente. Dourados, UFMS, 2000.

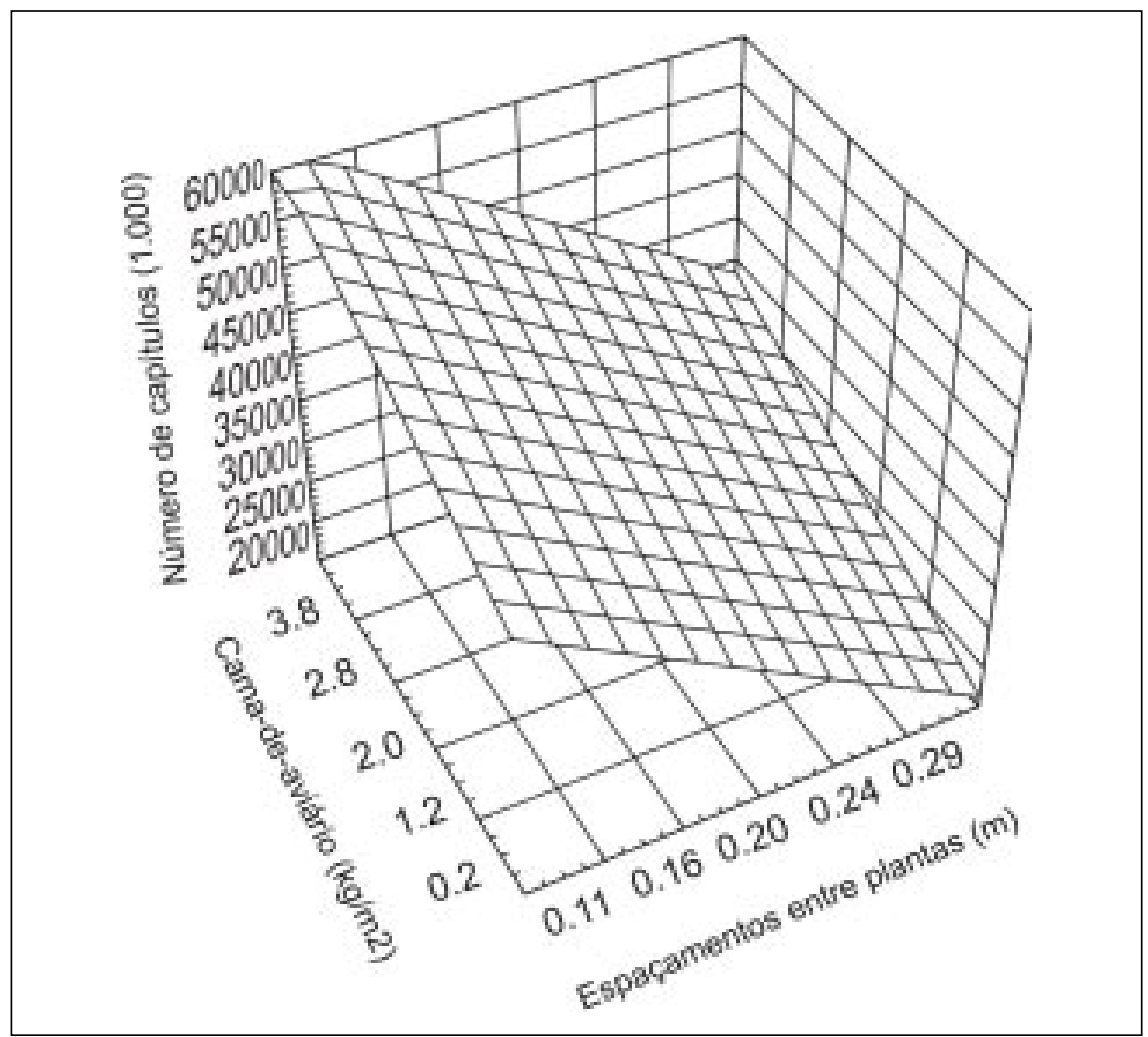

Figura 3. Número de capítulos florais da camomila (Chamomilla recutita) cv. Mandirituba em função do uso de cama-de-aviário (C) e de espaçamentos (E) entre plantas. C.V. $(\%)=$ 12,$96 ; \hat{y}=56936,1-121822 * * E+3430,99 * * C ; R^{2}=0,97 ; * * e^{o}-$ significativos a 1 e $10 \%$ de probabilidade, respectivamente. Dourados, UFMS, 2000. tos T3 e T4, respectivamente. Devido ao alto custo do osmocote, os autores recomendaram o uso do $\mathrm{T} 4$.

Os números dos capítulos florais aumentaram linearmente com as doses de cama-de-aviário e diminuíram com o aumento dos espaçamentos entre plantas (Figura 3), sendo o maior deles (56,57 milhões ha $\left.{ }^{-1}\right)$ obtido com o menor espaçamento entre plantas $(0,11 \mathrm{~m})$ associado com a maior dose de camade-aviário $\left(3,8 \mathrm{~kg} \mathrm{~m}^{-2}\right)$ e que foi a causa provável do aumento da massa seca dos capítulos florais (Figura 2). Isso porque houve pouca variação na massa por capítulo (média de 0,12 g) indicando ser esse caráter genotípico e, portanto, pouco variável com o ambiente. Situação semelhante foi observada por Ramos et al. (1999a), ao estudarem duas $(0,54 \mathrm{~m}$ entre elas), três $(0,36 \mathrm{~m})$ e quatro $(0,27$ $\mathrm{m})$ fileiras de plantas por canteiro e espaçamentos de 0,$200 ; 0,225 ; 0,257 \mathrm{e}$ $0,300 \mathrm{~m}$ entre plantas. Observaram que houve aumento da produção de massa fresca $\left(725,52 ; 937,40\right.$ e $\left.1447,82 \mathrm{~kg} \mathrm{ha}^{-1}\right)$ e do número de capítulos $(7,26,10,08 \mathrm{e}$ 15,28 milhões ha-1) com o número de fileiras de plantas por parcela. Em outro estudo realizado por Ramos et al. (1999b), o resultado foi diferente, pois houve variação de massa $(0,09$ a 0,13 g) com a variação das doses de camade-aviário $\left(0 ; 10\right.$ e $\left.20 \mathrm{t} \mathrm{ha}^{-1}\right)$ e de espaçamentos entre plantas $(0,20 ; 0,25$ e $0,30 \mathrm{~m}$ ). Os resultados diferentes também podem ser atribuídos às diferenças climáticas, principalmente variação da temperatura, das diferentes épocas dos estudos. Aguilera et al. (2000) observaram que o uso de $4,0 \mathrm{~kg} \mathrm{~m}^{-3}$ de adubo químico de liberação controlada (15-912) mais $6,0 \mathrm{~kg} \mathrm{~m}^{-3}$ de húmus de minhoca resultou nas maiores quantidades de capítulos florais, as quais ocorreram entre 42 e 61 dias após o transplante, para todos os tratamentos.

Dentre as características morfológicas dos capítulos florais, as alturas $(0,71$ a $0,81 \mathrm{~cm}$ aos 100 dias e 0,68 a $0,71 \mathrm{~cm}$ aos 116 dias após o transplante) e os diâmetros médios (1,96 a $2,13 \mathrm{~cm}$ aos 100 dias e 1,83 a $1,91 \mathrm{~cm}$ aos 116 dias após o transplante) não variaram significativamente entre os tratamentos, mas a redução após 100 dias de cultivo indica que a colheita da 
camomila em Dourados não deve ser feita após essa época. Os valores encontrados neste experimento, superaram os 0,52 e $1,60 \mathrm{~cm}$ de altura e diâmetro médios, respectivamente, obtidos por Corrêa Júnior (1994). Aguilera et al. (2000) também observaram pouca variação no diâmetro (média de 1,7 cm) dos capítulos florais da camomila em função dos tratamentos usados (adubo químico de liberação controlada 15-912, combinado com húmus de minhoca) e tendência à redução do diâmetro com o aumento dos dias após transplante, a partir de 50 dias.

O teor de óleo essencial dos capítulos florais não variou entre tratamentos e foi, em média, de 0,5\%. O óleo apresentou cor azul intensa e odor característico, como descrito para os óleos de boa qualidade e apropriados para a comercialização (Wagner e Bladt, 1996). Qualitativamente, as amostras apresentavam perfis cromatográficos semelhantes àqueles descritos na literatura (Figura 4), com pontos correspondentes com os princípios ativos presentes nos capítulos florais. A camomila apresenta como principais constituintes o óxido de bisabolol, com coloração amareloesverdeada $(\mathrm{Rf}=0,2)$; espatulenol, de cor violeta $(\mathrm{Rf}=0,25)$; bisabolol, de cor violeta clara $(\mathrm{Rf}=0,35)$; polienos, com coloração marrom $(\mathrm{Rf}=0,5-0,6)$; azuleno, de cor vermelho violeta $(\mathrm{Rf}=0,95)$ e THC/farneseno, de coloração azul-violeta $(\mathrm{Rf}=0,99)($ Wagner e Bladt, 1996; Medic-Saric et al., 1997).

\section{AGRADECIMENTOS}

Ao CNPq, pelas bolsas concedidas e à FUNDECT-MS, pelo apoio financeiro. A Maria da Conceição Guerra, pela colaboração nos trabalhos de laboratório da UFMS.

\section{LITERATURA CITADA}

AGUILERA, D.B.; SOUZA, J.R.P.; MIGLIORANZA, E. Efeito do adubo de liberação controlada e vermicomposto na produção de camomila (Matricaria chamomilla L.). Revista Brasileira de Plantas Medicinais, Botucatu, v.3, n.1, p.61-65, 2000.

ALVAREZ V., V.H. Avaliação da fertilidade do solo: superficies de resposta - modelos aproximativos para expressar a relação fator-resposta. Viçosa: UFV, 1991. 75 p.

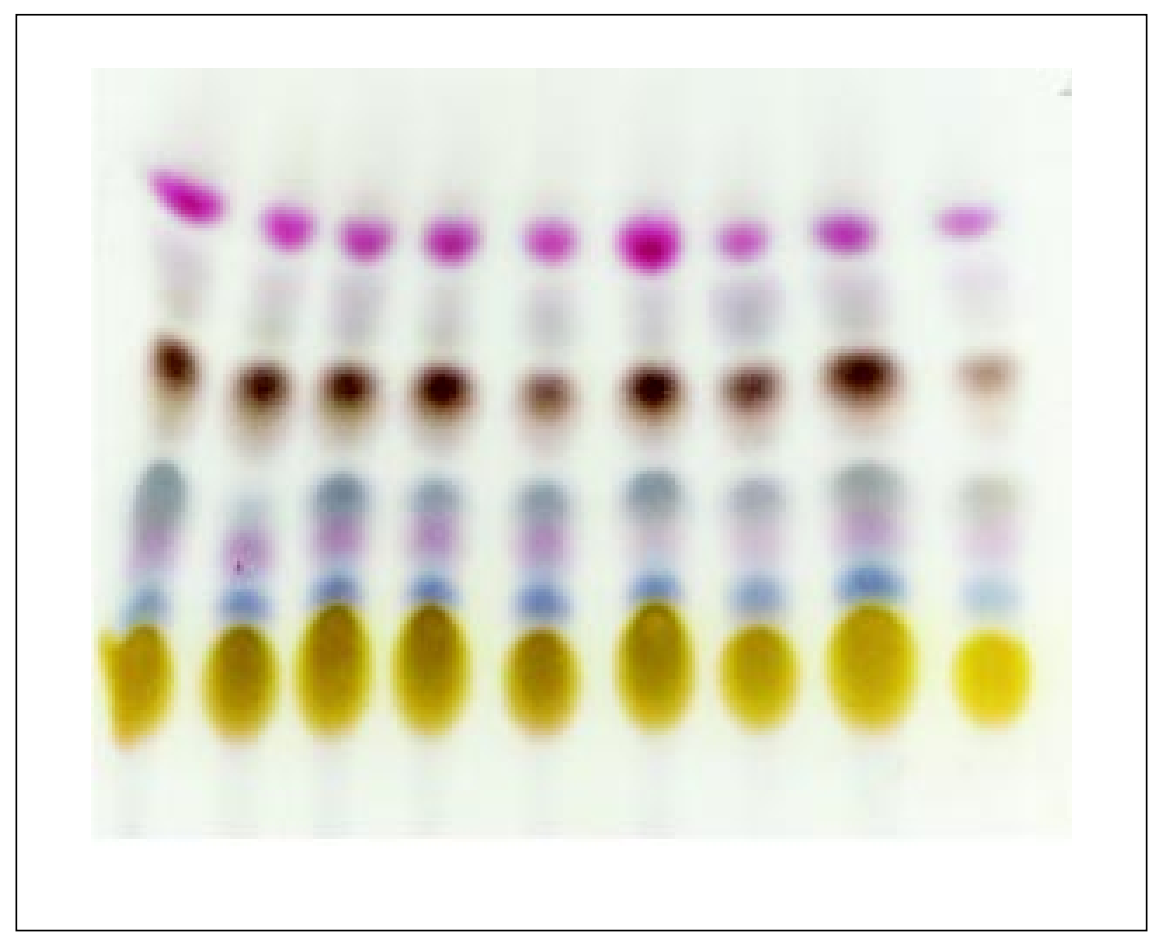

Figura 4. Perfil cromatográfico obtido em cromatografia em camada delgada de sílica-gel das amostras do óleo essencial dos capítulos florais da Chamomilla recutita obtidas dos nove tratamentos (espaçamentos entre plantas $(\mathrm{m})$ e cama-de-aviário $\left(\mathrm{kg} . \mathrm{m}^{-2}\right): 0,16$ e 1,2; 0,24 e 1,$2 ; 0,16$ e 2,$8 ; 0,24$ e 2,8; 0,20 e 2,$0 ; 0,11$ e 1,$2 ; 0,29$ e 2,$8 ; 0,16$ e 0,2 e 0,24 e 3,8, respectivamente). Sílica-gel $60 \mathrm{G}$, eluente: tolueno, acetato de etila P.A., 70:30, revelador: vamilina/sulfúrica, seguido de aquecimento. Dourados, UFMS, 2000.

ALISSON, F.E. Soil organic matter and its role in crop production. Amsterdam: Elsever Scientific, 1973. 637 p. ( Developments in Soil Science, 3). AMAT, A.G. Morfologia y anatomia comparadas de Chamaemelum nobile (L.) All., Chamomilla recutita (L.) Rauschert espécies adulterantes. Acta Farmaceutica Bonaerense, La Plata, v.1, n.2, p.8194, 1982.

BANZATTO, D.A.; KRONKA, S.N. Experimentação agrícola. Jaboticabal: FUNEP, 1989. 247 p.

BEZZI, A.; AIELlA, N.; GHIDINI, G. La coltivazione della camomilla nell'ltalia settentrionale: Vari tipi di camomilla comune coltivati in Trentino-Alto adige. L'Informatore Agrário, n.19, p.27-32, 1991.

CHANDRA, V.; KAPPOR L.D. Cultivation of Matricaria chamomilla L. in Índia. In: Academia Brasileira de Ciências. Anais... Rio de Janeiro, v.44, p.114-116, 1971.

CORRÊA JÚNIOR, C. Influência das adubações orgânica e química na produção de camomila \{Chamomila recutita (L.) Rauschert \} e do seu óleo essencial. Botucatu, 1994. 95 p. (Tese mestrado). UNESP.

CORRÊA JÚNIOR, C.; MING, L.C.; SCHEFFER, M.C. Cultivo de plantas medicinais, condimentares e aromáticas. 2. ed. Jaboticabal: FUNEP, 1994. $162 \mathrm{p}$.

CORRÊA JR., C.; TANIGUCHI, C. Aspectos da cultura de camomila no Estado do Paraná. Horticultura Brasileira, Brasília, v.10, n.1, p.52, 1992. $32^{\circ}$ Congresso Brasileiro de Olericultura, 1992.
DALla COSTA, M.A. Processo de produção agrícola da cultura da camomila no município de Mandirituba - PR. Curitiba, 2001. 69 p. (Tese mestrado). UFPR.

DI STASI, L.C. Plantas medicinais: arte e ciência. In: DI STASI, L.C. (Org.). Plantas medicinais: arte e ciência. Um guia de estudo interdisciplinar. São Paulo: UNESP, p.9-14, 1996. DONALÍSIO, M.G.R. Determinações preliminares do teor de óleo essencial em camomila cultivada no Brasil. Bragantia, Campinas, v.44, n.1,

EL-HAMIDI, A; SALEM, M; HAMD, H. The effect of fertilizer levels on growth, yield and oil production of Matricaria chamomilla. Lloydia, v.28, n.3, p.245-251. 1965.

FARIAS, M.R. Avaliação da qualidade de matérias-primas vegetais. In: Farmacognosia: da planta ao medicamento. Florianópolis: Ed. da UFSC, 1999. p.197-220.

FERREIRA, M.A.J.F.; BRAZ, L.T. Caracterização de cultivares de camomila de diferentes origens. Horticultura Brasileira, Brasília, v.13, n.1, p.81. 1995. $35^{\circ}$ Congresso Brasileiro de Olericultura, 1995. HEREDIA Z., N.A.; VIEIRA, M.C.; GARCIA, A.H. Agronomia-UFMS trabalha no controle de Diabrotica sp. com porongos como armadilha. SOBInforma, Campos dos Goytacazes-RJ, v.17, n.2, p.18, 1998.

MADUEÑO BOX, M. Cultivo de plantas medicinales. Madrid, 1973. $490 \mathrm{p}$.

MAIA, N.B.; FURLANI, A.M.C. Especiarias, aromáticas e medicinais. In: RAIJ, B.V.; CANTARELLA, H.; QUAGGIO, J.A.; FURLANI, A.M.C. Recomendações de adubação IAC, 1996. 285 p. (Boletim técnico, 100). p.4-7, 1985 . e calagem para o Estado de São Paulo. Campinas: 
MARTINS, E.R.; CASTRO, D.M.; CASTELLANI, D.C.; DIAS, J.E. Plantas medicinais. Viçosa: UFV- Imprensa Universitária, 1998. $220 \mathrm{p}$.

MEDIC-SARIC, M.; STANIC, G.; MALES, Z.; SARIC, S. Aplication of numerical methods to thin-layer chromatographic investigation of the main components of chamomile [Chamomilla recutita (L.) Rauschert] essencial oil. Journal of Chromatography A., v.776, p.335-360, 1997.

PENEVA, P.T. Cultural methods for medicinal chamomille. Rastenico "din-Nauki, v.21, n.2, p.39-44, 1984.

RAMOS, M.B.M.; VIEIRA, M.C.; HEREDIAZ., N.A. Produção de capítulos florais de Matricaria chamomilla $\mathrm{L}$. em função de números de fileiras e de espaçamentos entre plantas. In: JORNADA PAULISTA DE PLANTAS MEDICINAIS, 4. 1999, Ribeirão Preto. Programação e Resumos... Ribeirão Preto: UNAERP/UNESP, 1999a, p.64.
RAMOS, M.B.M.; VIEIRA, M.C.; HEREDIAZ., N.A.; SIQUEIRA, J.M. Produção e validação qualitativa do óleo essencial de capítulos florais de Matricaria chamomilla L. em função do uso de cama-de-aviário e de populações de plantas. Horticultura Brasileira, Brasília, v.17, n.3, 1999b. $39^{\circ}$ Congresso Brasileiro de Olericultura, 1999. ROBBERS, J.E.; SPEEDIE, M.K.; TYLER, V.E. Pharmacognosy and Pharmacobiotechnology, Internation Edition. London: Williams \& Wilkins, 1996. p.87.

RIBEIRO JR., J.I. Análises estatísticas no SAEG. Viçosa: UFV, 2001. 301 p.: il.

RODRÍGUEZ, F.M.; MOURELLE, J.F.; GUTIÉRREZ, Z.P. Actividad espasmolitica del extracto fluido de Matricaria recutita (Manzanilla) en órganos aislados. Revista Cubana de Plantas Medicinales, v.1, n.1, p.19-24, 1996.
SALAMON, I. Ecobiology of the chamomille (Chamomille recutita $\mathrm{L}$. Rauschert). Horticultura Brasileira, Brasília, v.12, n.2, p.226-229, 1994. SILVA, J.A.A. Plantas medicinais. Itajaí, SC 1999. CD-ROM.

TURRENT, A.; LAIRD, R.J. La matriz experimental Plan Puebla, para ensayos sobre prácticas de producción de cultivos. Agrociencia, n.19, p.117-143, 1975.

VIEIRA, M.C.; HEREDIA Z., N.A.; SANCHES, M.A.S. Produção da camomila cv Mandirituba em função do uso de nitrogênio e de cama-de-aviário. Horticultura Brasileira, Brasília, v.19, n.2, 2001. CD ROM. Trabalho apresentado no $41^{\circ}$ Congresso Brasileiro de Olericultura, 2001.

WAGNER, H.; BLADT, S. Plant drug analysis a thin layer chromatography atlas. 2.ed. Berlin: Springer, 1996.384 p. 